\title{
Diagnosis of Inherited von Willebrand Disease: A Clinical Perspective
}

\author{
Augusto B. Federici, M.D. ${ }^{1}$
}

von Willebrand disease (VWD) is the most frequent inherited disorder of hemostasis and is due to quantitative (types 1 and 3) or qualitative (type 2) defects of von Willebrand factor (VWF). Due to the large heterogeneity of VWF defects and to the external variables influencing VWF levels in the circulation, VWD diagnosis can be difficult, especially in relatively mild forms. Three criteria should be always satisfied for a correct VWD diagnosis: (1) a positive bleeding history since childhood; (2) reduced levels of VWF activity in plasma; and (3) autosomal dominant or recessive inheritance patterns within the family (in most cases). According to clinical prospective studies, a bleeding history in VWD patients should be derived from a detailed questionnaire, with calculated bleeding scores. The ristocetin cofactor activity is the most useful test for VWD screening in the general population because it reproduces in vitro the first VWF interactions with its platelet receptor; however other assays are required to identify and classify VWD types. The current classification (types $1,2 \mathrm{~A}, 2 \mathrm{~B}, 2 \mathrm{M}, 2 \mathrm{~N}$, and 3 ) is important to understand the basic mechanisms of VWF defects, to determine the risk of bleeding, and to select the best therapeutic approach. Molecular screening can be important to confirm phenotypic diagnosis for tracking VWF defects within families. Compared with hemophilia, most VWD patients show relatively mild bleeding symptoms. Therefore, prenatal diagnosis is required only for women already known to be carriers of VWD type 3. No spontaneous bleedings usually occur at birth in severe type 3 VWD. Neonatal diagnosis of VWD should always be compared with other affected members within the same family. Given that young children with VWD type 3 might carry deletions of VWF gene that predispose to the alloantibodies to VWF, every new child with VWD type 3 should be investigated intensively for VWF gene deletions before starting extensive therapy with exogenous VWF concentrates.

KEYWORDS: Inherited von Willebrand disease, von Willebrand factor, bleeding score, ristocetin cofactor activity, genetic and molecular diagnosis

When Erik von Willebrand in 1926 described a novel bleeding disorder in a large family from Foglo on the islands of Aaland in the Gulf of Bothnia, he provided an impressive and exhaustive description of its clinical and genetic features. Unlike hemophilia, the epitome of inherited bleeding disorders, both sexes were affected, and mucosal bleeding was the dominant symptom. Prolonged bleeding times (BTs) with normal platelet

\footnotetext{
${ }^{1}$ Angelo Bianchi Bonomi Hemophilia Thrombosis Center Department of Medicine and Medical Specialties, IRCCS Maggiore Hospital, Mangiagalli, Regina Elena Foundation and University of Milan, Milan, Italy.

Address for correspondence and reprint requests: Augusto B. Federici, M.D., Associate Professor of Hematology, Angelo Bianchi Bonomi, Hemophilia and Thrombosis Center, Department of Medicine and Medical Specialties, IRCCS Maggiore Hospital, Mangiagalli, Regina Elena, Foundation and University of Milan, Via Pace 9,
}

20122 Milano, Italy. E-mail: augusto.federici@unimi.it.

Hereditary von Willebrand Disease and Acquired von Willebrand Syndrome: Clinical Manifestations, Diagnosis, and Management; Guest Editors, Jan J. Michiels, M.D., Ph.D., and Emmanuel J. Favaloro, Ph.D., M.A.I.M.S.

Semin Thromb Hemost 2006;32:555-565. Copyright (C) 2006 by Thieme Medical Publishers, Inc., 333 Seventh Avenue, New York, NY 10001, USA. Tel: +1(212) 584-4662.

DOI 10.1055/s-2006-949661. ISSN 0094-6176. 
counts was the most important laboratory abnormality, and a functional disorder of the platelets associated with systemic lesion of the vessel wall was suggested as a possible cause of the disorder. However, he called the disease "hereditary pseudohaemophilia." To complicate the issue further, some authors subsequently called the disorder "vascular hemophilia."

Only in the 1950s was it demonstrated that the prolonged BTs in these patients was associated with reduced factor (F) VIII, but we had to wait until the 1970s to clarify that the deficiency of a new factor, called von Willebrand factor (VWF) and different from FVIII, was actually responsible for the disease. Surprisingly, the reduction of this factor caused low FVIII levels, pointing to the close relationship between the two proteins. In the 1980s, the cloning of the VWF gene set the basis for unraveling the molecular causes of the disorder.

The history of von Willebrand disease (VWD) has been the subject of a review. ${ }^{1}$ In this review, I discuss the progress and the current problems of VWD diagnosis, 80 years after the original description by Erik von Willebrand.

\section{STRUCTURE-FUNCTION OF VWF AND ITS CHANGES DURING EARLY CHILDHOOD}

VWF is synthesized by endothelial cells and megakaryocytes. ${ }^{2}$ The gene coding for VWF has been cloned and located at chromosome $12 \mathrm{p} 13.2$. It is a large gene composed of $\sim 178$ kilobases and containing 52 exons. A noncoding, partial, highly homologous pseudogene has been identified in chromosome 22 . The pseudogene spans the gene sequence from exon 23 to $34 .^{3}$ The primary product of the $V W F$ gene is a protein with 2813 amino acids made of a signal peptide of 22 amino acids (also called a prepeptide), a large propeptide of 741 amino acids, and a mature VWF molecule containing 2050 amino acids. In keeping with a recently proposed nomenclature, ${ }^{4}$ numbering starts from the first amino acid of the signal peptide, so 764 is the first amino acid of the mature protein. Different protein regions, corresponding to four types of repeated domains (D1, D2, D', D3, A1, A2, A3, D4, B, C1, C2) of cDNA, are responsible for the different binding functions of the molecule (Fig. 1). Mature VWF is the result of ordered intracellular processing, leading to the storage and/or secretion of a heterogeneous array of multimeric, multidomain glycoproteins, referred to as VWF.

VWF has two major functions in hemostasis. First, it is essential for platelet-subendothelium adhesion and platelet-to-platelet interactions, as well as platelet aggregation in vessels in which rapid blood flow results in elevated shear stress, a function partially explored in vivo by measuring the BTs. Adhesion is promoted by the interaction of a region of the $\mathrm{A} 1$ domain of VWF with glycoprotein (GP) Ib $\alpha$ on the

\section{Pseudo gene in Chromosome 22}

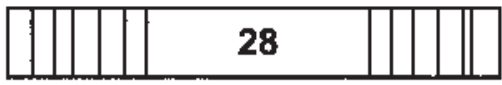

VWF gene in Chromosome 12

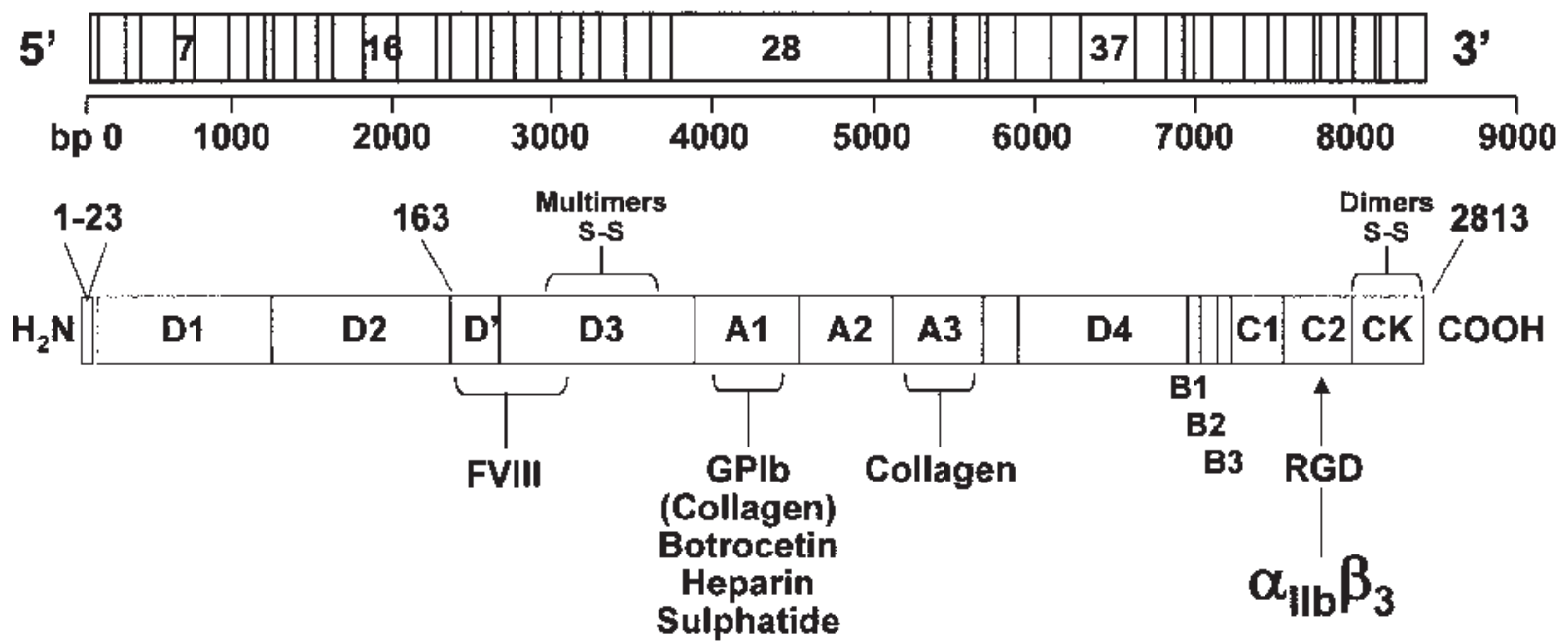

Figure 1 Schematic representation of the von Willebrand factor (VWF) gene located in chromosome 12 together with the pseudogene in chromosome 22. The main exons are indicated with the number of base pairs from $5^{\prime}$ to $3^{\prime}$ (above). DNA domain structure and pre-proVWF polypeptide: the pre-pro-VWF is indicated with amino acids numbered from the amino- (aa 1) to carboxy-terminal portions (aa 2813) of VWF. Note the important CK and D3 domains for formation of VWF dimers and multimers (below). The native mature subunit of VWF after the cleaving of the pre-pro VWF, is described with its functional domains: the VWF binding sites for factor (F) VIII ( $D^{\prime}$ and D3), glycoprotein Ib (GPIb), botrocetin, heparin, sulfatide, collagen (A1), collagen (A3), and the RGD sequence for binding to $\alpha_{\| 1 \mathrm{~b}} \beta_{3}$. 
platelet membrane. It is believed that high shear stress activates the A1 domain of the collagen-bound VWF by stretching VWF multimers into their filamentous form. Furthermore, GPIb $\alpha$ and VWF are also necessary for platelet-to-platelet interactions. ${ }^{2}$ The interaction between GPIbo and VWF can be mimicked in plateletrich plasma by addition of the antibiotic ristocetin, which promotes the binding of VWF to GPIb $\alpha$ of fresh or formalin-fixed platelets. Aggregation of platelets within the growing hemostatic plug is promoted by the interaction with a second receptor on platelets, GPIIbIIIa (or integrin $\alpha_{I I b} \beta_{3}$ ) which, once activated, binds to VWF and fibrinogen, recruiting more platelets into a stable plug. Both of these binding activities of VWF are highly expressed in the largest VWF multimers.

Second, VWF is the specific carrier of FVIII in plasma. VWF protects FVIII from proteolytic degradation, prolonging its half-life in the circulation and efficiently localizing it at the site of vascular injury. Each VWF monomer has one binding domain, located in the first 272 amino acids of the mature subunit ( $\mathrm{D}^{\prime}$ domain), which can bind one FVIII molecule, in vivo; however, only 1 to $2 \%$ of available monomers are occupied by FVIII. ${ }^{5}$ Therefore, any change in plasma VWF levels is usually associated with a concordant change in FVIII plasma concentrations. The correct nomenclature with abbreviations of the different FVIII/VWF activities, as approved by the Scientific Standardization Committees, Sub-Committee on VWF, of the International Society of Thrombosis and Haemostasis (ISTH-SSC on VWF), are summarized in Table $1 .^{6}$

The mature native VWF circulates in plasma of normal individuals at a concentration of 5 to $15 \mu \mathrm{g} / \mathrm{mL}$ : subjects with blood group $\mathrm{O}$ show lower plasma levels of VWF than those with blood group non-O. ${ }^{7}$ During fetal growth, VWF retains ultralarge molecular weight forms and plasma levels of VWF are higher in the newborn than in children: only after 6 months from birth, children show their actual levels of VWF and FVIII. ${ }^{8,9}$

Table 1 Recommended Nomenclature of Factor VIII/von Willebrand Factor Complex

\begin{tabular}{ll}
\hline Components & $\begin{array}{l}\text { Recommended } \\
\text { Nomenclature }\end{array}$ \\
\hline Factor VIII & \\
Protein & FVIII \\
Antigen & FVIII:Ag \\
Function & FVIII:C \\
Von Willebrand factor & \\
Mature protein & WWF \\
Antigen & WWF:Ag \\
Ristocetin cofactor activity & WWF:RCo \\
Collagen-binding capacity & WWF:CB \\
Factor VIII binding capacity & WWF:FVIIIB \\
\hline
\end{tabular}

Table derived from Mazurier et al. ${ }^{6}$
These data can explain why neonates with severe forms of VWD do not usually bleed, but should also be taken into consideration when VWD diagnosis is suspected in young children during their first 6 to 8 months of life.

\section{Classification of VWD}

The revised classification of VWD identifies two major categories, characterized by quantitative (types 1 and 3) or qualitative (type 2) VWF defects. ${ }^{10} \mathrm{~A}$ partial quantitative deficiency of VWF in plasma and/or platelets identifies type 1 , whereas type 3 is marked by the total absence or only trace amounts of VWF in plasma and platelets. Type 1 is easily distinguished from type 3 by the milder VWF deficiency (usually in the range of 10 to $40 \mathrm{U} / \mathrm{dL}$ ), the autosomal dominant inheritance pattern, and the presence of milder bleeding symptoms. ${ }^{11}$

Four type 2 VWD subtypes have been identified, reflecting different pathophysiologic mechanisms. Type $2 \mathrm{~A}$ and $2 \mathrm{~B}$ VWD are marked by the absence of high molecular weight VWF multimers in plasma; in type 2B, there is increased affinity for platelet GPIb-IX-V complex (GPIb $\alpha$ ). The identification of qualitatively abnormal variants with decreased platelet-dependent function and the presence of normal multimers on gel electrophoresis has led the addition of a new subtype, called $2 \mathrm{M}$. If this definition is followed and more stringent criteria are applied to VWD diagnosis, many cases previously identified as type 1 should now be classified as type $2 \mathrm{M}$ because they are caused by single missense mutations affecting VWF function but not its multimeric structure and assembly. Furthermore, type $2 \mathrm{~N}$ (Normandy) also shows a full array of multimers because the defect lies in the N-terminal region of the VWF molecule where the binding domain for factor VIII resides. This type is phenotypically identified only by an abnormal FVIII/VWF binding test: in fact, this test is always normal in mild hemophiliacs or carriers of hemophilia A. ${ }^{12}$ The current classification of VWD, summarized in Table 2, was proposed by Sadler ${ }^{10}$ in 1994 on behalf of the ISTH-SSC on VWF. A working party, composed by experts in the field, has the duty to prepare the updated classification of VWD within 2006.

\section{PREVALENCE AND FREQUENCY OF DIFFERENT VWD TYPES}

VWD is the most frequent inherited bleeding disorder, with a prevalence of up to $1 \%$ in certain geographic areas according to population studies. ${ }^{11}$ On the other hand, prevalence based on the number of patients registered at specialized centers ranges from four to 10 cases $/ 100,000$ inhabitants: symptomatic VWD patients requiring specific treatment are 50 to 100 per million. ${ }^{11}$

In the past, type 1 was reported as the most frequent form of VWD (Table 3). A recent retrospective 


\section{Table 2 Classification of von Willebrand Disease}

Quantitative deficiency of VWF
Type 1: Partial quantitative deficiency of VWF
Type 3: Virtually complete deficiency of VWF
Qualitative deficiency of VWF
Type 2: Qualitative deficiency of VWF
(A) Type 2A: Qualitative variants with decreased
platelet-dependent function associated with the absence
of high-molecular-weight VWF multimers
(B) Type 2B: Qualitative variants with increased affinity for
platelet GPIb 2
(C) Type 2M: Qualitative variants with decreased
platelet-dependent function not caused by the absence
of high-molecular-weight VWF multimers
(D) Type 2N: Qualitative variants with markedly decreased
affinity for factor VIII

WF, von Willebrand factor; GPIb $\alpha$, glycoprotein Ib $\alpha$.

(From Sadler JE. A revised classification of von Willebrand disease. Thromb Haemost 1994;71:520-523.)

study based on reappraisal of type 1 diagnoses after 10 years (1994 versus 2004) in 1234 VWD patients followed by 16 Italian hemophilia centers, found that VWD type 1 was present in only 671 (54\%) of 1234 patients, because most of previously diagnosed VWD type 1 patients were rediagnosed as type 2 according to their discrepant VWF activities (VWF:ristocetin cofactor activity $[\mathrm{RCo}] /$ antigen $[\mathrm{Ag}]$ ratio < 0.7). Age distribution of the 1234 Italian VWD patients was 5 to 86 years, with 267 (22\%) of 1234 cases age younger than 20 years. ${ }^{13,14}$

\section{GENERAL APPROACH TO THE DIAGNOSIS OF VWD}

Three main criteria should be satisfied for a correct VWD diagnosis: (1) positive bleeding history since childhood; (2) reduced levels of VWF activity; and (3) autosomal dominant or recessive inheritance patterns, in most cases. Given that de novo mutations of the $V W F$ gene cannot be excluded in a patient without any affected members within the family, a correct diagnosis of VWD should

Table 3 Frequency of von Willebrand Disease Types

\begin{tabular}{lclcc}
\hline Authors & $\begin{array}{l}\text { Number of } \\
\text { Patients }\end{array}$ & $\begin{array}{l}\text { Type } \mathbf{1} \\
(\mathbf{\%})\end{array}$ & $\begin{array}{l}\text { Type 2 } \\
(\mathbf{\%})\end{array}$ & $\begin{array}{l}\text { Type 3 } \\
(\%)\end{array}$ \\
\hline Tuddenham & 134 & 75 & 19 & 6 \\
Lenk et al & 111 & 76 & 12 & 12 \\
Hoyer et al & 116 & 71 & 23 & 6 \\
Awidi & 65 & 59 & 30 & 11 \\
Berliner et al & 60 & 62 & 9 & 29 \\
Federici et al & 1234 & 54 & 40 & 6 \\
\hline
\end{tabular}

(From Castaman G, Federici AB, Rodeghiero F, Mannucci PM. Von Willebrand's disease in the year 2003: towards the complete identification of gene defects for correct diagnosis and treatment. Haematologica 2003;88:94-108.) always require at least two criteria, namely, reduced levels of VWF activity and a significant bleeding history since childhood. Therefore, the analysis of the patient's bleeding history plays a major role in the decision made by the hematologists for the final diagnosis of VWD, especially in patients with borderline levels of VWF activity, close to those observed in normal individuals.

\section{STANDARDIZED CRITERIA FOR EVALUATION OF THE BLEEDING HISTORY: A BLEEDING SCORE}

Several attempts have been made recently by clinicians, experts in VWD, to evaluate the sensitivity and specificity of bleeding symptoms, which are important especially in the mild cases of type $1 \mathrm{VWD}$, with VWF:RCo levels $>30 \mathrm{U} / \mathrm{dL}$. In a multicenter study about the clinical presentation of type 1 VWD in obligatory carriers, it has been shown that menorrhagia and epistaxis are not good predictors of type $1 \mathrm{VWD}$, whereas cutaneous bleeding and bleeding after dental extractions should be considered the most sensitive symptoms. ${ }^{15}$ Therefore, a specific bleeding score has been proposed for general use in the diagnosis of VWD (Table 4). This bleeding score has been tested in affected and nonaffected members of 154 VWD families enrolled prospectively in a large European study, as well as in 200 normal individuals. ${ }^{16}$

\section{CLINICAL FEATURES AND BLEEDING SYMPTOMS IN DIFFERENT VWD TYPES}

The clinical expression of VWD is usually mild in most type 1 disease; severity increases in types 2 and 3 disease. In general, the severity of bleeding correlates with the degree of the reduction of VWF:RCo and FVIII:coagulant activity $(\mathrm{C})$ activities, but not with the magnitude of BT prolongation or with the patient's ABO blood type. Mucocutaneous bleeding (epistaxis, menorrhagia) is a typical manifestation of the disease and may even affect the quality of life. VWD may be highly prevalent in patients with isolated menorrhagia. ${ }^{11}$ Women with VWD may require treatment with antifibrinolytics, iron supplementation, or an estrogen/progesterone pills to control heavy menses. Bleeding after dental extraction is the most frequent postoperative bleeding manifestation. Given that FVIII:C is usually only slightly reduced, manifestations of a severe coagulation defect (hemarthrosis, deep muscle hematoma) are rare in type $1 \mathrm{VWD}$ and are mainly posttraumatic. In type 1 VWD bleeding after delivery is rare because FVIII/VWF levels tend to become normal at the end of pregnancy. Postoperative bleeding may not occur even in more severely affected type 1 VWD patients, but in type 3 VWD prophylaxis is always required. To date, only a few detailed descriptions of symptoms in VWD patients have been provided, ${ }^{17,18}$ but only one study took into account the differentiation 


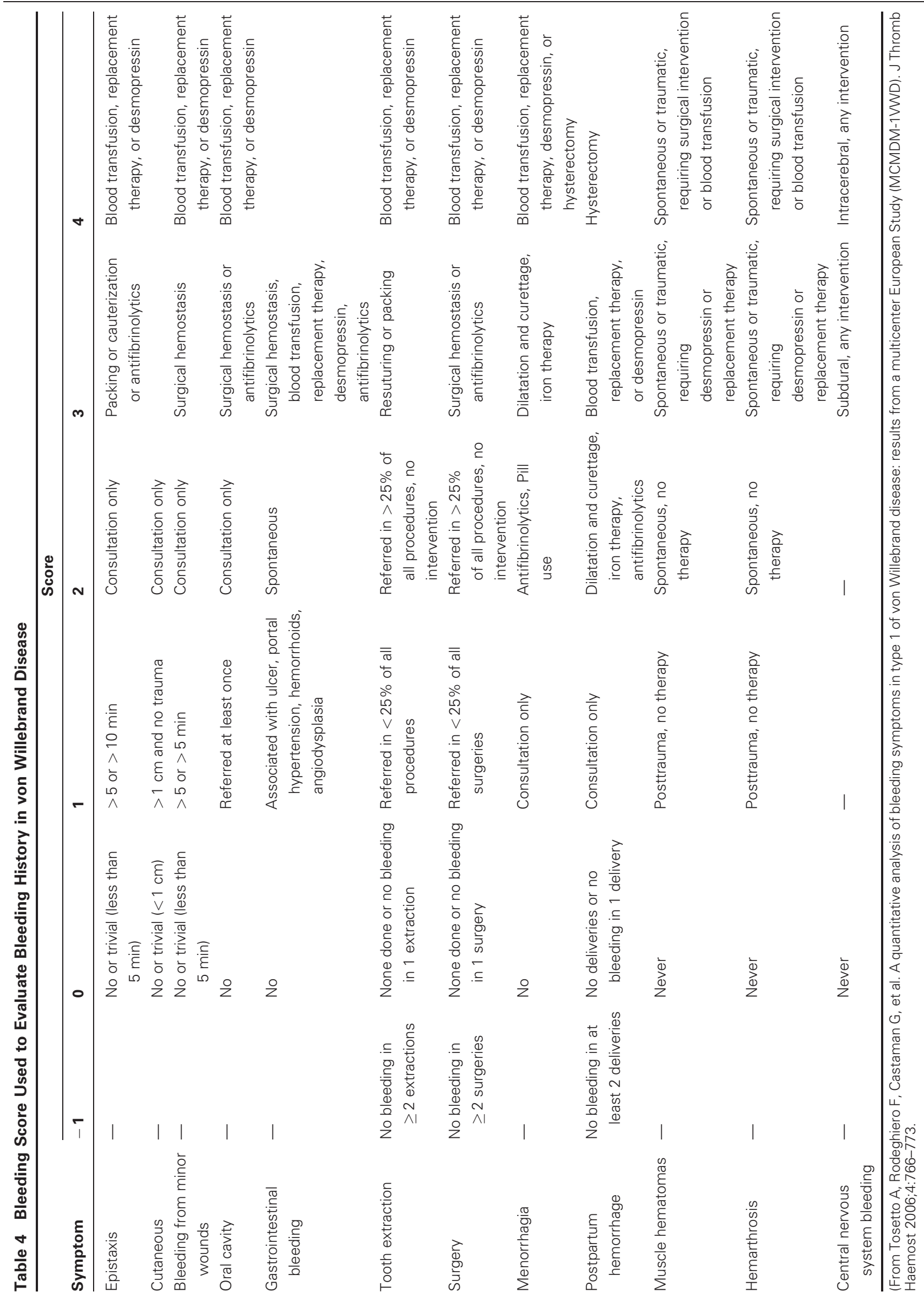

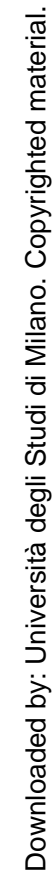


Table 5 Incidence (\%) of Bleeding Symptoms in Patients with von Willebrand Disease (VWD) and in Normal Subjects

\begin{tabular}{|c|c|c|c|c|c|c|}
\hline \multirow[b]{2}{*}{ Symptoms } & \multirow{2}{*}{$\begin{array}{l}\text { Iranian VWD } \\
\text { Type } 3 \\
(\mathrm{n}=348)\end{array}$} & \multicolumn{3}{|c|}{ Italian VWD $(n=1234)^{*}$} & \multicolumn{2}{|c|}{ Scandinavian } \\
\hline & & $\begin{array}{l}\text { Type } 1 \\
(\mathrm{n}=671)\end{array}$ & $\begin{array}{l}\text { Type } 2 \\
(\mathrm{n}=497)\end{array}$ & $\begin{array}{l}\text { Type } 3 \\
(n=66)\end{array}$ & $\begin{array}{l}\text { VWD } \\
(\mathrm{n}=264)\end{array}$ & $\begin{array}{l}\text { Normal Subjects } \\
(\mathrm{n}=500)\end{array}$ \\
\hline Epistaxis & 77 & 61 & 63 & 66 & 62 & 5 \\
\hline Menorrhagia & 69 & 32 & 32 & 56 & 60 & 25 \\
\hline Postextraction bleeding & 70 & 31 & 39 & 53 & 51 & 5 \\
\hline Hematomas & NR & 13 & 14 & 33 & 49 & 12 \\
\hline Bleeding from minor wounds & NR & 36 & 40 & 50 & 36 & 0.2 \\
\hline Gum bleeding & NR & 31 & 35 & 56 & 35 & 7 \\
\hline Postsurgical bleeding & 41 & 20 & 23 & 41 & 28 & 1 \\
\hline Postpartum bleeding & 15 & 17 & 18 & 26 & 23 & 19 \\
\hline Gastrointestinal bleeding & 20 & 5 & 8 & 20 & 14 & 1 \\
\hline Joint bleeding & 37 & 3 & 4 & 45 & 8 & 0 \\
\hline Hematuria & 1 & 2 & 5 & 12 & 7 & 1 \\
\hline Cerebral bleeding & NR & 1 & 2 & 9 & NR & 0 \\
\hline
\end{tabular}

*Bleeding symptoms in Italian patients have been recalculated recently according to the updated results of the Italian Registry of VWD and therefore are different from those reported previously. ${ }^{13,14}$

(From Federici AB, Castaman G, Mannucci PM. Guidelines for the diagnosis and management of VWD in Italy. Haemophilia 2002;8:607-621; Federici AB. Clinical diagnosis of von Willebrand disease. Haemophilia 2004:10:169-176; von Silwer J. Willebrand's disease in Sweden. Acta Paediatr Scand 1973;238:1-159; Lak M, Peyvandi F, Mannucci PM. Clinical manifestations and complications of childbirth and replacement therapy in 348 Iranian patients with type 3 von Willebrand disease. Br J Haematol 2000;111:1223-1229.)

NR, not reported.

according to the VWD types. ${ }^{13,14}$ The relative frequency of bleeding symptoms in three large series of patients with VWD diagnosed at specialized centers is reported and listed in Table 5.

\section{LABORATORY TESTING TO DIAGNOSE VWD TYPES: A FLOW CHART}

Once it is suspected that a patient has VWD because of a positive bleeding history since childhood, a set of different laboratory tests should be performed to make a definitive diagnosis of the VWD type. Due to the large heterogeneity of VWF defects and to the external variables influencing VWF levels in the circulation, the diagnosis of VWD, particularly type 1 , may require several laboratory tests to be repeated at different occasions (Table 6). The BT is usually prolonged, although it may be normal in patients with mild forms of VWD such as those with type 1 and normal platelet VWF content. ${ }^{19}$

Differential diagnosis of VWD types can be done by using these laboratory tests, following the flow chart already proposed by the guidelines for diagnosis and treatment of VWD in Italy (Fig. 2). Type 3 VWD can be diagnosed in case of unmeasurable VWF:Ag levels. A proportionate reduction of both VWF:Ag and VWF:RCo with a $\mathrm{RCo} / \mathrm{Ag}$ ratio $>0.7$ suggests type 1 VWD. If the VWF:RCo/Ag ratio is $<0.7$, type 2 is diagnosed. Type 2B VWD can be identified in the presence of an enhanced ristocetin-induced platelet agglutination (RIPA; $<0.8 \mathrm{mg} / \mathrm{mL}$ ), whereas types $2 \mathrm{~A}$ and $2 \mathrm{M}$ cause low RIPA $(>1.2 \mathrm{mg} / \mathrm{mL})$. Multimeric analysis in plasma is necessary to distinguish between type $2 \mathrm{~A}$ VWD (lack of the largest and intermediate multimers) and type $2 \mathrm{M}$ VWD (all the multimers present). Type $2 \mathrm{~N}$ VWD can be suspected in the presence of discrepant values for FVIII and VWF:Ag (ratio < 1) and diagnosis should be confirmed by the specific test of VWF:FVIIIC. In type $1 \mathrm{VWD}$ the ratio between FVIII and VWF:Ag is always $\geq 1$ and the severity of type 1 VWD phenotype usually can be evaluated from platelet VWF measurements. ${ }^{19}$

Additional tests for VWD diagnosis include the closure time (CT) and assays of VWF activity based on

Table 6 Clinical and Laboratory Parameters Used for von Willebrand Disease (VWD) Diagnosis

\footnotetext{
Patients at risk for VWD

Clinical history: lifelong mucocutaneous and postoperative bleeding; symptoms are sometimes present in other family members (bleeding score)

Screening tests: prolonged bleeding time (may be normal); normal platelet counts; prolonged PTT (may be normal)

Diagnosis and definition of VWD*

VWF antigen [a]

VWF:ristocetin cofactor activity [b]

Factor VIII [c]

VWF multimeric structure on low-resolution gels [e]

Diagnosis of VWD types*

RIPA [d]

VWF multimeric structure on high-resolution gels [e]

Platelet VWF content [f]

Factor VIII binding assay [g]
}

* For the use of these tests, see the diagnostic flow chart reported in Fig. 2 and also by Federici et al. ${ }^{13}$

PTT, partial thromboplastin time; VWF, von Willebrand factor; RIPA ristocetin-induced platelet agglutination. 


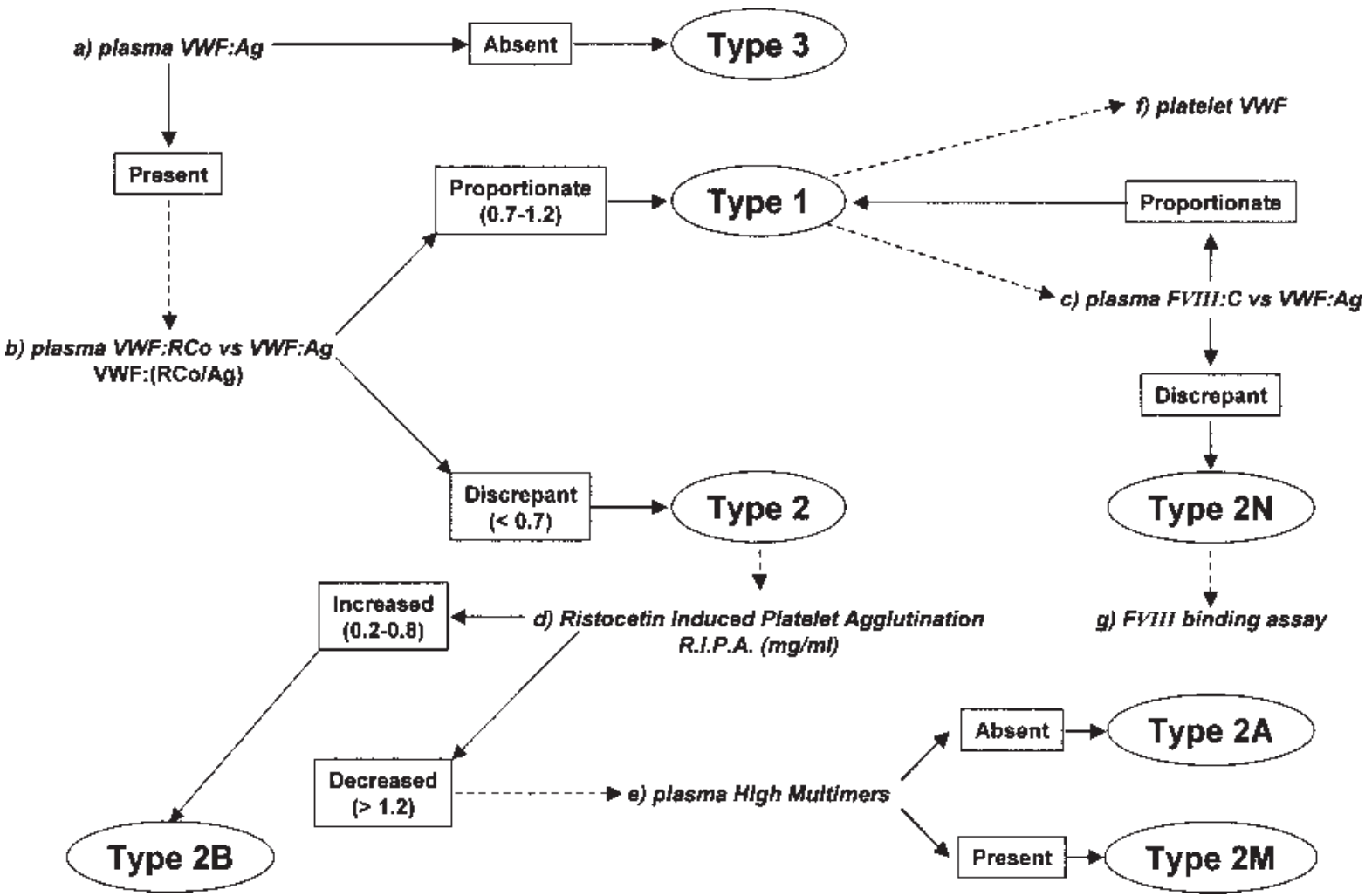

Figure 2 Flow chart proposed in diagnosis of different von Willebrand disease (VWD) types (see description in the text).

collagen-binding activity (CB). Evaluation of CT with the Platelet Function Analyser (PFA-100; DadeBehring, Marburg, Germany) gives a rapid and simple measure of VWF-dependent platelet function at high shear stress: the analysis can be performed in whole blood and therefore has been proposed instead of BT in children. This system is sensitive and reproducible for VWD screening, but is not always specific and must be performed always together with other VWF tests. ${ }^{11}$ Assays are also available for VWF:CB and the ratio of VWF:CB to VWF:Ag appears useful for distinguishing types 1 and 2: however, results can vary according to the type of collagen sources. ${ }^{20}$ In Italy, we have introduced VWF:CB in our panel of assays together with VWF:RCo since 1998, and VWF:CB has been proven to be a very useful additional test to discriminate between types $2 \mathrm{~A}$ and $2 \mathrm{M}$ VWD. ${ }^{21}$

\section{CLINICAL EXPRESSION OF VWF DEFECTS: SEVERE, MODERATE, AND MILD FORMS OF VWD}

Type 3 is always severe by definition because it is characterized by unmeasurable VWF level in both plasma and platelets and by low amounts of FVIII:C $(<20 \mathrm{U} /$ $\mathrm{dL}$ ). Conversely, types 1 and 2 VWD are very heterogeneous and their clinical presentation is related strictly to the circulating levels of VWF functional activities, measured as VWF:RCo. In the last 5 years, an international prospective study on the use of desmopressin in severe forms of VWD has been performed by five European hemophilia centers in the framework of the 5th Project sponsored by the European Community, and the results have been published. ${ }^{22}$ For the first time, the Steering Committee of this study made an attempt to define patients with severe VWD forms, using levels of FVIII/VWF activities as criteria for severity. Patients with severe VWD were defined as those who were characterized by a lifelong history of bleeding (including at least two episodes of blood loss severe enough to require replacement therapy) and by the presence of at least one of the following laboratory abnormalities: BTs $>15$ minutes, VWF:RCo $<10$ IU/dL, FVIII:C $<20 \mathrm{IU} / \mathrm{dL}^{22}$ Similar criteria have been used by the Steering Committee of the Italian National Registry on VWD to evaluate retrospective data on 1234 VWD patients collected from 16 hemophilia centers on behalf of the Italian Association of Hemophilia Centers. ${ }^{14}$ Therefore, a mild form of VWD can be diagnosed when patients show a mild personal and family bleeding history with levels of VWF:RCo 10 to $40 \mathrm{U} / \mathrm{dL}$ and/or FVIII:C 20 to $50 \mathrm{U} / \mathrm{dL}$, with or without prolonged BT. Conversely, the diagnosis of VWD can be considered for patients with values close to normal ranges. The definition of disease versus reduced levels of normal VWF is difficult in the absence of bleeding history in other members of the family, as reported recently. ${ }^{23,24} \mathrm{~A}$ pictorial representation of the 


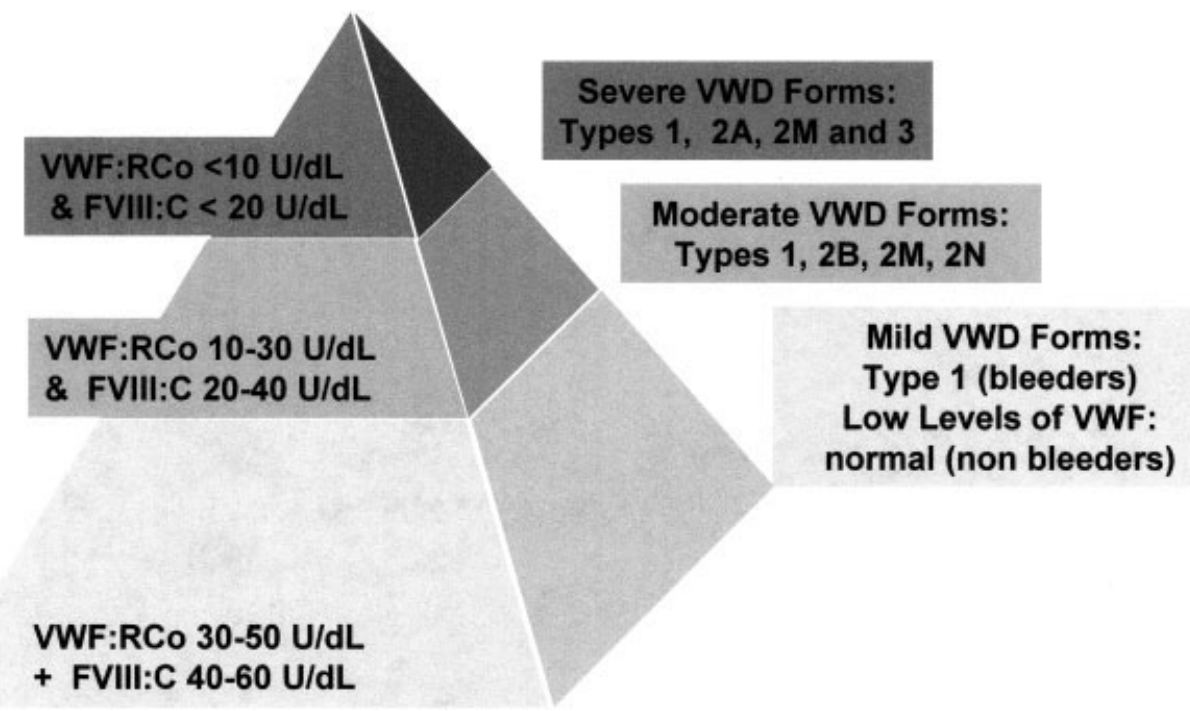

Figure 3 Pictorial representation of the three different degrees of von Willebrand disease (VWD) severity according to levels of factor (F) VIII/von Willebrand factor (VWF) activities: severe, moderate, and mild VWD forms. In the upper part of the pyramid, the most severe VWD forms (types $3,2 \mathrm{~A}, 2 \mathrm{M}, 1$ ) are included with levels of $\mathrm{VWF}: \mathrm{RCo}<10 \mathrm{U} / \mathrm{dL}$ and/or FVIII:coagulant activity $(\mathrm{C})<20 \mathrm{U} / \mathrm{dL}$. The moderate VWD forms (types 1, 2B, 2M, 2N) with levels of VWF:RCo 10 to $30 \mathrm{U} / \mathrm{dL}$ and/or FVIII:C 20 to $40 \mathrm{U} / \mathrm{dL}$ and the mild VWF forms (VWF:RCo 30 to $50 \mathrm{U} / \mathrm{dL}$ and/or FVIII:C 40 to $60 \mathrm{U} / \mathrm{dL}$ ) are described in the middle portion and in the base of the pyramid. Due to the physiological changes of VWF and of the variability of the assays, a very mild VWD form with values of VWF:RCo and/or FVIII:C $>40 \mathrm{U} /$ $\mathrm{dL}$ can be diagnosed only when these low-borderline levels of FVIIINWF activities are associated with personal and family bleeding history. Therefore, the lower the levels of VWF:RCo or FVIII:C, the higher is the probability of a current VWD diagnosis: in this sense, the severe VWD forms might represent the tip of the iceberg of a large number of moderate and mild VWF defects.

different degrees of VWD severity according to levels of FVIII/VWF activities is shown in Fig. 3.

\section{PATTERNS OF INHERITANCE}

The inheritance pattern of VWD type 3 is autosomal recessive. In type $2 \mathrm{VWD}$ patients, the pattern of inheritance is mainly autosomal dominant, even though rare cases with recessive pattern have been reported. ${ }^{11}$ The inheritance of the mild type $1 \mathrm{VWD}$ is usually autosomal dominant, with variable phenotype and penetrance. Despite its high prevalence, the precise genetic cause of type 1 VWD is still elusive in most cases, especially in those with a mild phenotype. In type $1 \mathrm{VWD}$, in fact, several genetic and nongenetic factors are likely to contribute to the wide variability of the clinical and laboratory phenotype. About $60 \%$ of the variations in VWF plasma are due to genetic factors, with $\mathrm{ABO}$ group accounting for only $30 \%$. In type $\mathrm{O}$ subjects the VWF level is 25 to $35 \%$ lower than in nonO individuals. ${ }^{7}$ Additional factors other than the $V W F$ gene, such as platelet polymorphisms, have been proposed to modify the bleeding tendency of type $1 \mathrm{VWD}$, as reported. ${ }^{25}$

\section{MOLECULAR AND PRENATAL DIAGNOSIS OF VWD}

Cloning the $V W F$ gene has allowed the identification of several suitable restriction fragment length polymor- phisms (RFLP), which demonstrate the cosegregation of VWD phenotype with haplotype-specific RFLP patterns in family members of different kindred with VWD. ${ }^{11}$ Understanding of the crucial segments of VWF involved in the interaction with GPIbo initially prompted the fruitful search for mutations in exon 28 of the $V W F$ gene, which encodes for the $\mathrm{A} 1$ and $\mathrm{A} 2$ domains of mature VWF, as shown in Fig. 1 (review by Castaman et $\mathrm{al}^{11}$ ). The search for mutations has been extended to additional VWF exons encoding for the other functional domains of VWF. The most frequent mutations reported in types $2 \mathrm{~A}, 2 \mathrm{~B}, 2 \mathrm{M}$, and $2 \mathrm{~N}$ are listed in Table 7 according to the specific VWF domains and are currently updated on the Web site organized on behalf of the ISTH-SSC on VWF (www.shef.ac.uk/vwf).

Most type 2A cases are due to missense mutations in the A1 domain, with R1597W or Q or Y and S1506L accounting for $\sim 60 \%{ }^{26}$ The majority of type $2 \mathrm{~B}$ cases are due to missense mutations in the A1 domain; 90\% are caused by R1306W, R1308C, V1316M, and R1341Q mutations (Table 7). A few heterogeneous mutations are responsible for type $2 \mathrm{M}$ cases and are also located within the A1 domain. Therefore, most mutations are expressed and the mutated recombinant VWF has been compared with others found within the same domain. ${ }^{27} \mathrm{~A}$ recurrent mutation in type $2 \mathrm{M}$ Vicenza has been reported recently in families from Europe $(\mathrm{R} 1205 \mathrm{H})$, associated with a second nucleotide change (M740I) and identified exclusively in some families from the Vicenza area. ${ }^{28,29}$ Missense mutations in the 
Table 7 Most Frequent Mutations in Types 2A, 2B, 2M, and 2N According to VWF Domains

\begin{tabular}{|c|c|c|}
\hline Localization of VWF Defects & VWD Types & VWF Mutations Associated with Specific Types \\
\hline \multirow[t]{2}{*}{ D2 domain } & Type 2A (formerly IIC) & F404insNP - R436del6 - N528S - G550R \\
\hline & & C623W - A625insG \\
\hline \multirow[t]{5}{*}{ D'-D3 domains } & Type 2N & R782W - G785E - E787K - C788R \\
\hline & & C788Y - T791M - Y795C - M800V \\
\hline & & R816W - R816Q - H817Q - R854Q \\
\hline & & R854W - C858F - D879N - Q1053H \\
\hline & & C1060R - C1225G \\
\hline \multirow[t]{2}{*}{ D3 domain } & Type 2M (formerly 1 Vicenza) & R1205H - Y1146C \\
\hline & Type 2A (formerly IIE) & C1143Y - C1173R \\
\hline \multirow[t]{10}{*}{ A1 domain } & Type 2B (formerly IIB) & P1266L - H1268D - C1272G - C1272R \\
\hline & & M1304insM- R1306Q - R1306L - R1306W \\
\hline & & R1308C - R1308P - I1309V - S1310F \\
\hline & & W1313C - V1314F - V1314L - V1316M \\
\hline & & P1337L - R1341L - R1341Q - R1341W \\
\hline & & L1460V - A1461V \\
\hline & Type 2M & G1324S - G1324A - E1359K - F1369I \\
\hline & & I1425F - Q1191del1- K1408deIK \\
\hline & Type2M/2A & L1276P - R1374C - R1374H -C1458Y \\
\hline & & R1374R \\
\hline \multirow[t]{7}{*}{ A2 domain } & Type 2A (formerly IIA) & G1505E - G1505R - S1506L - F1514C \\
\hline & & K1518E - L1540P - S1543F - Q1556R \\
\hline & & L1562P - R1597G - R1597Q - R1597W \\
\hline & & V1604F - V1607D - V1609R - P1627H \\
\hline & & I1628T - G1629R - V1630F - E1638K \\
\hline & & L1639P - P1648S - L1657I - V1665E \\
\hline & & G1672R \\
\hline CK domain & Type 2A (formerly IID) & C2773R \\
\hline
\end{tabular}

For an updated list of VWF mutations according to VWD types, refer to the Web site www.shef.ac.uk/vwf. VWF, von Willebrand factor; VWD, von Willebrand disease.

FVIII-binding domain at the amino-terminal portion of VWF are responsible for type $2 \mathrm{~N}$ (reviewed by Mazurier et $\mathrm{al}^{12}$ ).

Despite its high prevalence, the precise genetic cause of type 1 VWD is still elusive in most cases, especially in those with a mild phenotype. The molecular defects are distributed within the entire $V W F$ gene. More information about molecular diagnosis of VWD type 1 will be available as soon as the data of the European project entitled Molecular and Clinical Markers for Diagnosis and Management of Type 1 VWD are published later in 2006.

In type $3 \mathrm{VWD}$, partial or total gene deletions have been reported initially (reviewed by Eikenboom $^{30}$ ). Notably, homozygous states for gene deletion may be associated with the appearance of alloantibodies against VWF, which may render replacement therapy ineffective and stimulate anaphylactic reactions to treatment. ${ }^{11}$ Gene defects of type 3 VWD patients from different populations have now been studied, but there was no founder effect and mutations were distributed throughout the entire $V W F$ gene. ${ }^{31}$
Compared with hemophilia, most VWD patients show relatively mild bleeding symptoms. Therefore, prenatal diagnosis is required mainly if parents are already known to be carriers of VWD type 3, with gene defects identified in their first affected child. Neonatal diagnosis can be performed in children born from parents with VWF defects already characterized, but phenotypic diagnosis of VWD should always be confirmed later in the child's life and compared with the other affected members within the same family. Given that young children with VWD type 3 might carry deletions of $V W F$ gene that predispose them to the alloantibodies to VWF, every new child with VWD type 3 should be investigated intensively by searching deletions using Southern blot analysis (as reported by Shelton-Inloes et $\mathrm{al}^{32}$ ) before extensive therapy with exogenous VWF concentrates is started.

\section{CONCLUSIONS}

VWD is the most frequent inherited bleeding disorder. The prevalence of clinically relevant VWD has not been 
estimated directly in the population, but a figure of $\sim 100$ /million, similar to that of hemophilia A, is widely accepted. A detailed collection of the bleeding history with calculation of the bleeding score is essential to identify patients with VWD in the presence of mild defects of VWF by laboratory testing. The phenotypic diagnosis is still the most accessible approach to a correct VWD diagnosis, taking into account the difficulties and costs of molecular diagnosis. However, molecular diagnosis can be useful to confirm and track specific VWF defects within VWD families.

\section{ACKNOWLEDGMENTS}

A few data on diagnosis and management of VWD are from the Italian Registry of VWD sponsored by a grant from the Italian Ministry of Health. Definitive data on the retrospective and prospective studies obtained from this registry are in progress. We thank all of the Members of the Italian Association of Haemophilia Centres who participated in this Registry and contributed to the preparation of the Guidelines for Diagnosis and Therapy of VWD in Italy.

\section{REFERENCES}

1. Nilsson I. The history of von Willebrand disease. Haemophilia 1999;5(suppl 2):7-11

2. Ruggeri ZM. Structure of von Willebrand factor and its function in platelet adhesion and thrombus formation. Best Pract Res Clin Haematol 2001;14:257-279

3. Mancuso DJ, Tuley EA, Westfield LA, et al. Human von Willebrand factor gene and pseudogene: structural analysis and differentiation by polymerase chain reaction. Biochemistry 1991;30:253-269

4. Goodeve A, Eikenboom JCJ, Ginsburg D, et al. A standard nomenclature for von Willebrand factor gene mutations and polymorphisms. On behalf of the ISTH SSC Subcommittee on von Willebrand factor. Thromb Haemost 2001;85:929-931

5. Vlot AJ, Koppelman SJ, Bouma BN, Sixma JJ. Factor VIII and von Willebrand factor. Thromb Haemost 1998;79:456465

6. Mazurier C, Rodeghiero F. Recommended abbreviations for von Willebrand factor and its activities. Thromb Haemost 2001;85:929-931

7. Gill JC, Endres-Brooks J, Bauer PJ, Marks WJ, Montgomery $\mathrm{RR}$. The effect of $\mathrm{ABO}$ blood group on the diagnosis of von Willebrand disease. Blood 1987;69:1691-1695

8. Katz JA, Moake JL, McPherson PD, et al. Relationship between human development and disappearance of unusually large von Willebrand factor multimers from plasma. Blood 1989;73:1851-1858

9. Andrew M, Paes B, Milner R, et al. Development of the human coagulation system in the healthy premature infant. Blood 1988;72:1651-1657

10. Sadler JE. A revised classification of von Willebrand disease. Thromb Haemost 1994;71:520-523

11. Castaman G, Federici AB, Rodeghiero F, Mannnucci PM. Von Willebrand's disease in the year 2003: towards the complete identification of gene defects for correct diagnosis and treatment. Haematologica 2003;88:94-108

12. Mazurier C, Goudemand J, Hilbert L, Caron C, Fressinaud E, Meyer D. Type $2 \mathrm{~N}$ von Willebrand disease: clinical manifestations, pathophysiology, laboratory diagnosis and molecular biology. Best Pract Res Clin Haematol 2001;14: 337-348

13. Federici AB, Castaman G, Mannucci PM. Guidelines for the diagnosis and management of VWD in Italy. Haemophilia 2002;8:607-621

14. Federici AB. Clinical diagnosis of von Willebrand disease. Haemophilia 2004;10:169-176

15. Rodeghiero F, Castaman G, Tosetto A, et al. The discriminant power of bleeding history for the diagnosis of von Willebrand disease type 1: an international, multicenter study. J Thromb Haemost 2005;3:2619-2626

16. Tosetto A, Rodeghiero F, Castaman G, et al. A quantitative analysis of bleeding symptoms in type 1 of von Willebrand disease: results from a multicenter European Study (MCMDM-1VWD). J Thromb Hemost; 2006. In press

17. von Silwer J. Willebrand's disease in Sweden. Acta Paediatr Scand 1973;238:1-159

18. Lak M, Peyvandi F, Mannucci PM. Clinical manifestations and complications of childbirth and replacement therapy in 348 Iranian patients with type 3 von Willebrand disease. Br J Haematol 2000;111:1236-1239

19. Mannucci PM, Lombardi R, Bader R, et al. Heterogeneity of type I von Willebrand's disease: evidence for a subgroup with an abnormal von Willebrand factor. Blood 1985;66: 796-802

20. Favaloro EJ. Collagen binding assay for von Willebrand factor (VWF:CBA): detection of von Willebrand's disease (VWD), and discrimination of VWD subtypes, depends on collagen source. Thromb Haemost 2000;83: 127-135

21. Federici AB, Canciani MT, Forza I, et al. Ristocetin cofactor and collagen binding activities normalized to antigen levels for a rapid diagnosis of type 2 von Willebrand disease: single center comparison of four different assays. Thromb Haemost 2000;84:1127-1128

22. Federici AB, Mazurier C, Berntorp E, et al. Biological response to desmopressin in patients with severe type 1 and type 2 von Willebrand disease: results of a multicenter European study. Blood 2004;103:2032-2038

23. Sadler JE. Von Willebrand disease type 1: a diagnosis in search of a disease. Blood 2003;101:2089-2093

24. Sadler JE, Rodeghiero F. Provisional criteria for the diagnosis of VWD type 1. J Thromb Haemost 2005;3:775-777

25. Kunicki TJ, Federici AB, Salamon DR, et al. An association of candidate gene haplotypes and bleeding severity in von Willebrand disease type 1 pedigree. Blood 2004;104:23592367

26. Meyer D, Fressinaud E, Hilbert L, et al. Type 2 von Willebrand disease causing defective von Willebrand factordependent platelet function. Best Pract Res Clin Haematol 2001;14:349-364

27. Lyons SE, Bruck ME, Bowie EJW, et al. Impaired cellular transport produced by a subset of type IIA von Willebrand disease mutations. J Biol Chem 1992;267:4424-4430

28. Schneppenheim R, Federici AB, Budde U, et al. Von Willebrand disease type $2 \mathrm{M}$ "Vicenza" in Italian and German patients: identification of the first candidate mutation (G3864A; R1205H) in 8 families. Thromb Haemost 2000; $83: 136-140$ 
29. Castaman G, Missiaglia E, Federici AB, Schneppenheim R, Rodeghiero F. An additional candidate mutation (G2470A; $\mathrm{M} 740 \mathrm{I})$ in the original families with von Willebrand disease type $2 \mathrm{M}$ Vicenza and the G3864A (R1205H) mutation. Thromb Haemost 2000;84:350-351

30. Eikenboom JCJ. Congenital von Willebrand disease type 3: clinical manifestations, pathophysiology and molecular biology. Best Pract Res Clin Haematol 2001;14:365-379
31. Baronciani L, Cozzi G, Canciani MT, et al. Molecular characterization of a multiethnic group of 21 patients with type 3 von Willebrand disease. Thromb Haemost 2000;84: 536-540

32. Shelton-Inloes BB, Chebab FF, Mannucci PM, et al. Gene deletion correlates with the development of alloantibodies in von Willebrand disease. J Clin Invest 1987;79:14591465 